New Zealand Journal of Industrial Relations, 21(2): 171-177

\title{
COMMENTARY
}

\section{Return to Work - The New Zealand Experience Under the Accident Compensation Scheme}

\section{Ross Wilson *}

On the 1st of April 1974 New Zealand embarked on a bold experiment. We abolished the tort action for personal injury and established a comprehensive, national, no-fault accident compensation scheme. The abolition of the common law right to sue was certainly regarded by jurists as a major step. The American Journal of Comparative Law described it in sombre tones as "an unparalleled event in our cultural history, the first casualty among the core legal institutions of the civilised world". It wasn't a step taken lightly and the Royal Commission recommendations on which the reform was based were subjected to public debate and legislative scrutiny for more than five years. As A.J. Faulker M.P. commented in Parliament on 3 October 1972:

Over the last five years every Tom, Dick and Harry, every expert with a satchel, has come to Parliament and tried to destroy the Woodhouse recommendations, but it has stood up to all that onslaught.

Twenty-two years later we have a legislative shambles created by the ill informed legislators and advisers of the 1990s, funding difficulties created by unwise political concessions to the employer lobby, and an administration struggling to survive, let alone achieve successful return to work and rehabilitation programmes.

In this paper I intend to briefly examine the fate of rehabilitation and return to work programmes in the course of that journey from sage idealism to ideological insanity. I believe that a pre-requisite to successful rehabilitation is a statutory framework which creates a conducive environment for employers, injured workers and the administrators. I will therefore attempt to analyse the changing statutory framework in New Zealand and the responses of the various parties to it from 1974 to the present time. I will, of course, do so from the personal perspective of a union official who has taken an active interest in our Accident Compensation Scheme for more than 20 years, and was a member of the Board of the Accident Compensation Corporation for almost six years. 
Rehabilitation was a primary objective of the 1967 Woodhouse Royal Commission. The Commission recommended the scheme be based on five principles (including rehabilitation):

- Community Responsibility

- Comprehensive Entitlement

- Real Compensation

- Complete Rehabilitation

- Administration Efficiency

Strong rehabilitation objectives were included in the founding legislation, the Accident Compensation Act 1972. They required the Accident Compensation Commission (ACC) to:

. . take all practical steps to promote a well co-ordinated and vigorous programme for the medical and vocational rehabilitation of persons who become incapacitated as a result of personal injury by accident. . .

and directed that the programme would have as its objective:

(a) Their restoration as speedily as possible to the fullest physical, mental and social fitness of which they are capable having regard to their incapacity and

(b) Where applicable, their restoration to the fullest vocational and economic usefulness of which they are capable and

(c) Where applicable their reinstatement or placement in employment.

So there was no statutory right to vocational rehabilitation, no job security rights and no specific provisions relating to the "return to work"; but strong directive provisions underpinned the exercise of the ACC's discretion.

Another important provision in the 1972 Act was the permanent pension. This was a pension assessed on the basis of loss of earning capacity which, once assessed, could never be reduced. The concept was to ensure that the injured person was given a strong incentive to return to work and not live in fear of the compensation authority for the rest of his or her working life. Unfortunately, from an early stage, the ACC was reluctant to make permanent pension assessments and a steadily increasing number of people who were partially incapacitated remained on earnings related compensation at 80 percent of pre-accident earnings.

Similarly, although some financial incentives could be offered to employers on a case by case basis there were no strong monetary incentives, or statutory requirements, which encouraged employers to take an interest in rehabilitating injured workers back to work. On manybuilding sites injured workers were sent their dismissal notices soon after they were taken away in the ambulance. 
At workplace level the necessary education work was not, and never has been, done. Many workplaces continued "no light duties" policies and a resistance to disabled workers.

Whatever the reason, within a few years the ACC had begun to develop ways of terminating or reducing weekly earnings compensation, rather than developing innovative and effective return to work policies.

In the early 1980s this seemed to be the ACC's primary focus. If an injured worker was certified as partially fit, an administrative assessment was made of that person's notional earnings and the earnings compensation was reduced accordingly. These notional earnings assessments often had no relationship with reality or real jobs and I frequently found railway track workers with fists the size of hams who had been assessed as fit for clerical work and were in desperate financial straits because their family income had been suddenly terminated.

This abuse of an unintended legislative power was itself terminated in 1985 with an amendment to the Act which by then was the 1982 Accident Compensation Act.

The Parliament in 1982 had recognised the failure of the ACC to achieve its rehabilitation objectives and had further strengthened the rehabilitation clauses in the legislation by including a specific statutory directive that the ACC, "... shall place great stress upon rehabilitation". This legislative act of frustration had little effect on the administrators and by 1985 , with a change of government, Parliament was receptive to an amendment which abolished the ACC power to reduce or terminate earnings-related compensation on the basis of light duty assessments. It did so in response to submissions from the union central organisation, that doing so would give the ACC a strong financial incentive to put in place effective rehabilitation programmes to get injured workers off its books, rather than removing them by administrative decree as it had been doing. (The process had been for the ACC to make a notional assessment of earnings based on the injured person's capacity to do "light work" and deduct the notional earnings from pre-accident earnings for the purpose of calculating earnings-related compensation payable.)

I joined the Board the following year and regret to have to confess failure in achieving the rehabilitation objectives during the following five years, despite endless policy debates and external reviews. Legislative change was needed, but was avoided by the ACC's patron in government (Geoffrey Palmer, then Labour Deputy Prime Minister and later Prime Minister), because of a fear of what the Treasury ministers might do to the scheme if legislation was mooted.

By this time it was clear that the strong rehabilitation provisions in the 1972 and 1982 Acts were at least one strong component of an appropriate statutory framework. The Court of Appeal in a 1990 decision (ACC v Broadfoot [1990] 3 NZLR 169) observed that " . . the provisions recognise that the rehabilitation of incapacitated persons . . . is an important social and economic concern for New Zealand ...."

By this time unemployment in New Zealand was at an all time high, ACC's rehabilitation programmes and policies were still ineffective, the number of partially incapacitated workers 
remaining permanently on earnings related compensation had increased, and there was a growing concern about the increasing funding requirements of the scheme.

The incoming National Government immediately established a Review Committee almost exclusively made up of business men with no previous experience in accident compensation. The ensuing 1992 Accident Rehabilitation and Compensation Insurance Act reflected their lack of understanding of this fairly complex area of social policy.

I shall focus only on the changes which impacted (actually or potentially) on return to work. As Professor Terence Ison has observed a paramount change was in the relationship of compensation and rehabilitation. It had been traditional for compensation to be a statutory right and for rehabilitation to be discretionary (but within the context of strong statutory objectives). The 1992 changes shifted the emphasis by purporting to make rehabilitation a right, and making earnings related compensation after the first 12 months more discretionary.

The strong statutory rehabilitation objectives were swept away to be replaced by a so-called "right to vocational rehabilitation" and diluted objectives (s.22). The right is, even in its statutory context, an illusion. There can be no real right to vocational rehabilitation without a right to a job and an identified employer to provide it. The vocational rehabilitation which might be available under section 22 is also heavily proscribed:

It is only available if the Corporation is satisfied that the provision or payment is necessary to enable the person to obtain or maintain employment;

It must be ". . . cost effective for the Corporation";

It is available on an individual rehabilitation programme for only one year (extended to two years in some cases).

On the income security/worker incentive side, the permanent pension - the cornerstone of the Woodhouse Scheme - was abolished and earnings related compensation made subject to a work capacity test after 12 months. In essence, the old light duty assessments were reintroduced, again providing the administrators with an easier option than rehabilitating an injured worker back into work.

As Professor Ison has observed, "if sections 37 and 49 were read literally, almost anyone who was not bedridden would have the 85 percent capacity for some kind of unavailable work for which that person would be suited". However, the political impact of implementation was likely to be major (10,000 people dumped off the scheme), the assessment processes were found to be complex to develop and legally challengeable, and the work capacity provisions have yet to be implemented.

The combined failure to achieve a statutory framework and programmes which encourage a return to work, including the abolition of the permanent pension reflecting loss of earning capacity, has left the ACC in 1996 with the number of partially incapacitated workers on long term earnings released compensation steadily increasing and staying on the scheme longer. The 1996 response to this is a further Parliamentary Bill which further weakens the vocational rehabilitation provisions in the Act and gives ACC a broader and more authoritarian power 
to terminate earnings compensation for injured people who may be assessed as "fit for work" even if that work does not exist.

The weakening of the rehabilitation provisions and the absence of any "job security" rights has been exacerbated by an increasingly hostile approach from employers. I think this has been caused by two developments. The government and the ACC itself have created extensive publicity about fraud and abuse, based on extrapolations of evidence from other countries, rather than New Zealand research. This has created a climate in which it is becoming a matter of some shame and embarrassment to be an injured person receiving support from ACC.

The second development is experience rating of premiums which was introduced by the 1992 Act. Again Professor Ison warned that the Canadian experience has been that experience rating creates an adversarial situation and specifically, in the context of rehabilitation, has resulted in such illegitimate practices as:

* Pressing claimants to return to work too soon.

* Requiring claimants to report for work as a form of harassment or degradation when there is no available work that they are fit to do.

* $\quad$ Creating "light work" programmes that do not involve genuine work or which only involve work that is unsuitable for the condition of the claimant.

* Communicating directly with the attending doctor, sometimes seeking confidential medical information, sometimes pressing for a claimant to be certified as "fit for light work" but in any event, interfering with the confidentiality of the doctor/patient relationship.

Unfortunately this has also been the New Zealand experience since 1992 in many industries where claims and cost control are the focus rather than genuine rehabilitation and return to work initiatives.

The economic incentive which experience rating provides to employers can result in a positive approach and a recognition of the cost-benefit of good return to work programmes, but there are signs that, on balance, the effect is negative. The government response to the widespread public outcry as the 1992 Act impacted on injured people and their caregivers has been to set up a series of reviews. One of these ministerial review committees noted in its August 1994 report that, at that time:

\footnotetext{
... there appears to be little emphasis on vocational rehabilitation leading to re-employment. Indeed some case managers have, we understand, said that it is not part of their function to promote re-employment.
}

The committee concluded that the primary reason for this situation was experience rating; by hiring an employee who is thought to be vulnerable to further injury, an employer risks rating disadvantage. 
Having described the New Zealand experience, or at least my viewpoint of it, it is appropriate that I conclude by attempting to answer some of the questions raised. In short, what can we learn from the New Zealand experience? My personal conclusions are as follows:

1. There is certainly a need to get the statutory framework right. I think the strong statutory requirements in the 1972 and 1982 Acts had real value but need to be supplemented by the right for an injured worker to return to the pre-accident job within a specified period. We need to be careful to ensure that such a "right" doesn't become an obligation on a worker to accept unsuitable work.

2. There needs to be specific and carefully focused financial incentives to encourage employers to make the necessary workplace modifications. Again we need to ensure that the worker is valued and it is not just a subsidy that attracts the employer. This raises the issue of education.

3: There must be a sustained educational campaign at workplace level directed at both management and workers. We have come a long way in recent years in outlawing discrimination on the grounds of disability and the Human Rights legislation in New Zealand has the potential to have a huge and positive impact for disabled workers. But enforcement of these human rights must be accompanied by education.

4. A national rehabilitation plan should be developed and put in place. A succession of reports in New Zealand have recognised this failing and such a policy and other steps are needed to enable ratification of International Labour Convention no.159 of 1983 on Vocational Rehabilitation and Employment (Disabled Persons).

5. The ACC experience rating system should be abolished.

6. Joint employer/union task forces should be established at industry level to develop return to work codes of practice and programmes.

7. Specialist services should be developed for the placement in suitable employment of disabled persons. We have an excellent model in New Zealand with Workbridge, a specialist government-funded employment agency.

8. Assessment services need to be appropriate. The ACC in New Zealand is taking some promising new initiatives. A new vocational rehabilitation unit set up in the region I live in (Wellington) has had 120 workers referred who had been off work for between one and eleven years. Each highly skilled case manager has a workload of 40 (compared to the usual 120-200). It has been estimated that the $\$ 600,000$ invested has already saved a million dollars with good vocational rehabilitation, assessment, counselling and job placement services.

9. At workplace level there must be a creative approach for alternative work. In many workplaces, the workers themselves are the untapped source of that innovation. A safe return to a rewarding job is a more achievable objective if there is a combined approach from employers, ACC, workers and their unions, and the injured worker. 
An important part of maintaining an injured worker's motivation is to ensure that the link with workmates is kept alive during the period of absence from work.

10. Finally, the cornerstone of the Woodhouse concept, the permanent pension assessed on the basis of loss of earning capacity, must be reinstated so that the injured worker can be assured of some income security but also given an incentive to improve his or her economic position without the fear that that income base will be reduced. 